\title{
Symbiotes or Benevolent Microbes and Vitamines
}

\author{
How They Assist in the Life Processes of Higher Organisms: A New Theory \\ By May Tevis
}

THE world of science has recently been startled by a new and revolutionary theory concerning the so-called benevolent microbes. It has long been known, indeed, that the bodies of animals contain not only the pathogeni. germs which produce dis ease, but other microbes which are apparently harmless. A well-known French savant, M. Paul Portier, professor at the Oceanographic Institute has been studying these non-pathological micro vanced the novel hypothesis that has recently adnon-injurious, but are actually beneficial and indeed essential to the vital processes of higher organisms.

It is M. Portier's belief that symbiosis, i.c.., the lif in common of two organisms which are mutually heneficial to each other, is a universal phenomenon. The classic example of this sort of communal life is the lichen, since every lichen is not a single plant, as it appears to be, but consists, in reality, of two plants, a Pungus and an alga, which livo together in harmony. According to $M$. Portier there are no simple organisms except bacteria, all the higher or ganisms being in reality twofold, consisting, that is of the organism itself and of the micro-organism which are distributed throughout its tissues and play an important and necessary part in the processes of

To these minute collaborators in the vital func tioning of the organism the name symbiotes has been given. These symbiotes, which are very plastic and very active have been isolated and proven to be capable of life outside their host. While widely $d$ is tributed throughout the body they are found princ pally in certain organs, particularly in the pancreas aud the reproductive glands; they rarely occur in tho liver.

During the last year or so M. Portier has published several memoirs concerning his studies of symbiotes in the Compies Rendus of the French Acad emy of Sciences and elsewhere. Furthermore he has just published a volume entitled Les Symbiotes (The Symbiotes), in which he gives voluminous dat concerning his experiments with a large variety of animals, ranging from insects to vertebrates, alon this line. We are greatly indebted for the informa tion in the present article to an admirable review of the latter Prom the pen of Henry de Varigny, whic appeared recently in the Bibliotheque Universelle (Lausanne), since the work in question has not yet reached this country.

M. Portier gained his first idea of symbiotes through the study of certain caterpillars of the $m$ cro-lepidopters, such as the genus Nepticula. These caterpillars inhabit minute tunnels which they excavate in the thickness of leaves. They are absolutely aseptic and live upon crushed plant cells whose con tent is accessible to the digestive juices. Othe caterpillars, such as that of the Gracilaria Syringella, are also aseptic at the beginning of their existence before they desert their tunnel to live outside. Liv ing then upon more resistant cells they crush them imperfectly. But upon quitting their tunnels they become infected and their digestive canal is full of microbes living upon cellulosic debris which they render soluble. Here we have the beginning of beneficial association since the microbes live upo the cellulose while the insect lives upon the contents the cellulose while the insect lives upon the contents
of the cells liberated by the dissolving of the celluof the cells liberated by the dissolving of the cellu
lose. Again the digestive juice of those insects whic lose. Again the digestive juice of those insects whic ing cellulose, yet the larvae are enabled to develo by means of microbes which live upon wood by means of cytolysis afterwards supporting the life of the larvae. In the caterpillars of Nonagria and of Sesia, these well-fed microbes penetrate the epitheSesia, these well-fed microbes penetrate the epithe
lial cells of the intestines and there become liquefied there is an intercellular digestion of the microbe by the intestinal cell. Some of them pass into the blood where they are intercepted and absorbed by the leucocytes or white blood corpuscles, while some of them escape this fate and become encysted in the tissues. They pass of their own accord into the eggs and there multiply, and when the egg develops the larva is already provided with its symbiotic micro-organism. Thus in this case symbiosis is ac tually hereditary, and this seems to be intentional upon the part of Bame Nature, since the tissue which coutain the most of these auxiliary microbes re the reserves of fat adjoining the reproductive glands. These inclusions exist in all insects and have also been found in all vertebrate animals thus par in vestigated.

M. Portier has even succeeded in cultivating the symbiotes found in vertebrates, the easiest culture to make being those from the lower forms of vertebrates. He has established the fact that the sym biotes of birds and mammals require a temperature of about $40^{\circ} \mathrm{C}$., while for those of the lower vertebrates $25^{\circ} \mathrm{C}$. is sufficient. It has been proved that the culture takes place through the skin which de velops upon the surface, but it is evident that the passage of the tissue into the midst of the culture constitutes a critical period for the symbiote which it does not always survive. A curious circumstance is that the best culture of symbiotes is yielded by a tissue which has just passed through a state of in ense physiolog:cal functioning.

As seen in the culture the symbiotes are highly polymorphous. They are generally in the form of bacteria of medium length, but by varying the culure medium they can be transformed into shor bacilli and even into ordinary micrococci or into large spherical micrococci-or again into highly mobile short bacilli or into immobile filaments. All these are reduced to fragments by the presence of antiseptics. Thus we see that they are highly mal leable from the morphological point of view.

They are equally malleable likewise from the physiological point of view. The optimum tempera ture varies according to the origin. When the sym blote is derived from a frog or a toad, $25^{\circ} \mathrm{C}$. is a suf ficiently high temperature, while from $42^{\circ} \mathrm{C}$. to $45^{\circ} \mathrm{C}$. is require when it comes from a mammal or a bird. Thus we see that it produces races which are adapted to the heat of the surrounding medium however, all symbiotes of whatever origin are capable of adapting themselves to both these extreme and even to temperatures of from $50^{\circ} \mathrm{C}$. to $60^{\circ} \mathrm{C}$ $\left(122^{\circ} \mathrm{F}\right.$. to $140^{\circ} \mathrm{F}$.)

In spite of this comparatively great resistance to heat, symbiotes perish ordinarily when in a moist medium at less than $100^{\circ} \mathrm{C}$. However, they can be trained so as to resist a temperature of $110^{\circ} \mathrm{C}$., or even $117^{\circ} \mathrm{C}$. In the dry state they will resist $140^{\circ} \mathrm{C}$ but at $150^{\circ} \mathrm{C}$. they do not survive more than half an hour.

All antiseptics are fatal to them, the amount and time required being variable. If such experiment be arrested before death ensues symbiotes are obtained whose culture is slower and more difficult and an aberration of form is exhibited.

$$
\text { how SYMBotes assist in NUTRITION }
$$

M. Portier is convinced that symbiotes preside over two sorts of phenomena in the process of nutritionsimplification and destruction on the one hand and building up or synthesis on the other. When furnished carbohydrates they render them very oxidisble reducing Fehling's liquid just as the organism does. They transform glycerine into dioxyacetone they seem, indeed; to transform proteic substances into acid amines in the same manneras does the organism. From the synthetic point of view they also behave like the organism, since when furnished with sac charose and a nitrate they manufacture a polysac charid which is very similar to glycogen. As a matter of fact, according to M. Portier, it is really the organism itsele.

So far as is now known the symbiotes probably enter the organism with food by way of the alimen tary canal. When inoculated experimentally subcutaneously or into the circulatory system they are en irely innocuous, producing no reaction.

One of the most important features of the author' theory is his identification of the symbiotes with th elements of the cell known as mitochondria. These are minute bodies which exist in all cells whether of animals or plants except in most of the bacteria. They are also known as b:oplasts, leucites, vesicles, etc. They are usually in the form of small spherical bodies, but sometimes occur as filaments composed of grains, or even as rod-like kodies. M. Portier of grains, or even as rod-like lodies. M. Portier
is convinced that these mitochondria, a definite num. er of which exist in each cell, are really symbiotes. Various investigators have differed greatly as to the function of the mitochondria. Thus Guillermond has shown that they elaborate starch; Policard, that they produce hemoglobin; Mullon, that they make pigment, etc. M. Portier harmonizes these discrepancies by declaring that the mitochondria are really symbiotes-independent organisms feasting at the same table with higher organisms. The symbiote, in other words, is a highly polymorphous form of bacteria.

Certain histologists raise the objection that the mitochondria are not always capable of being cultivated in vitro. The author of this theory answers the said objection in a highly ingenious and interesting manner. He observes that there is no more reason why the mitochondria should be able to reproduce themselves at all times than for men or animals to possess the same prerogative. In men and animals old age causes the loss of reproductive powers, while in the mitochondria the same result is occasioned by the fulfilment of their physiologic rôle. When a mitochondria elaborates any product whatever it beccmes a sac containing the said product. In thls condition the mitochondria loses its power to repro duce itselp by division and remains a mere envelop. The mitochondria which reproduces itself is the one which has not yet become specialized.

Vital operations are of two sorts-functional activity involving the destruction of reserve material and the liberation of energy and functional repose during which the reserves are elaborated by means of synthesis; as Claude Bernard has strikingly expressed it: "Life is creation." Both these phe nomena occur alternately in the same cell and in the same symbiote according to M. Portier-but the symbiote not only manufactures a food reserve but is totally transformed into such an aliment and is entirely consumed at the proper time. The symbiotes share with their sister bacteria an enormous power of syythesis of the most complex and various sub stances. Bacteria are even capable of manufacturing protoplasm, albumenoid matter from simple inorganic substances, while, on the other hand, there seems to be no organic compound in nature which cannot be disintegrated into its elements by some scrt of bacteria.

M. Portier's view as to the part played by symbiotes can be best understood by studying concrete examples. There are certain living creatures, namely, the bacteria, which are sufficient to themselves in the matter of nutrition. Hence they may be termed autotrophic; these possess neither symbiotes nor mitochondria-they are themselves symbiotes or mitochondria and derive from inorganic matter the material from which to manufacture organic matter. namely their own protoplasm. All other living creatures, whether plants or animals, contain symbiotes and are, therefore, termed heterotrophic. With the exception therefore of bacteria all living organisms present a condition of symbiosis.

What then is the role of the cell? In the first place it appears to limit the number of symbiotes contained. Furthermore, it appears to constitute by means of its cytoplasm and its nucleus the chemical milieu which surrounds the symbiote and from whence the latter extracts the raw material required for its activities.

SYMBOTES AND VITAMINES

A highly interesting point with respect to vitamines is raised by M. Portier, which will undoubtedly rouse wide interest and possible controversy among men of science. It is only a few years ago that the well-known English scientist, Caspar Funk, made the startling announcement that certain wasting diseases, such as scurvy, beri-beri, etc., are really maladies of malnutrition and are due to the lack of certain in dispensable elements in the food of the victims of such diseases. These elements were termed vitamines b5 Funk. These vitamines are supposed to exist in certain portions of pruit, seeds and vegetables mor than in others. Thus they are eontained in the outer coatings of rice, wheat and other cereals and for this reason polished rice and white flour (made
from the inner part of the wheat) are imperfoct 
food, incapable of supporting life unless supplemented by other foods containing the vitamines, i.e., certain acid amines which are indispensable to life, of which the former have been deprived. But Portier holds the opinion that such maladies are really due to a deficiency of symbiotes, or what he calls a state of a-symbiosis. Accord.ng to Funk the sterilizatlon of foods, as in canned vegetables, kills the vitamines, and for th:s reason such foods tend to produce scurvy. But according to Portier sterilization kills the symbiotes. He has proved by experiments that the latter perish at a temperature of about $120^{\circ} \mathrm{C}$. and he po:nts out that th:s is the very temperature a wh ch vitamines are supposed to be destroyed, re marking that it is much eas:er to believe in the death of the living organisms known as symbiotes than in the dis:ntegrat:on of a vitamine, which as a matter of fact has been proved not to dissolve until the tem perature of $233^{\circ} \mathrm{C}$. is attained.

One of Fuuk's most convincing experiments was the feeding of mice with bread which had been prev:ously treated with alcohol. When fed upon this bread alone the mice soon died, but when the alcohol in wh:ch the bread had been soaked was added to in wh:ch the bread had been soaked was added to
the bread the mice continued to thrive. Funk explains this by saying that the alcohol has absorbed the vitamines and carried them away with it. Por tier declares in his turn that the alcohol has re moved the symbiotes. The latter are found abundantly in bran, and if the bran be treated with alcohol and the alcohol then evaporated the residual liquid w:ll produce an abundant culture of symbiotes. Symbiotes resist alcohol and also resist heat up 10 $120^{\circ} \mathrm{C}$. One of Funk's most telling arguments is that the decortication of rice and other cereals occasion phenomena of malnutrition, wh:ch he ascribes as we have said, to the removal of the vitamines, but Portier claims that the phenomenon is due to a lack of symbiotes. Living symbiotes are found in bran and in the integuments of seeds in general. But in the seed they have already been transformed into sacs containing reserve products. and if an animal is given cereals deprived of the coatisgs of the grain, it is given a food lacking in symbiotes.

But Funi was able to restore pigeons suffering from polyneuritis through de-vitaminized food by administering to them vitamines in the form of a crystallized substance and this substance contains no symbiotes. Port:er, however, responds gallantly to this argument by saying that doubtless the vitamine is one of the products of the activity of the symbiote. The same restorative result can be obtained, there fore, by administer:ng either vitamines or symbiote tc the victim of malnutrition. As a matter of fact this view appears to be supported by a striking experiment made by Portier and Bierry. They injected living symbiotes into animals in a state of a-vitaminosis, i.e., almost at the point of death through malnutrition. The animals were immeliately resurmalnutrition. The animals were immetiately
rected exactly as when vitamines are injected.

It has long been acknowledged that certain plants such as the legum nosae possess symbiotic bacteria and that these assist them in obtaining their prope nutrition. It is but a step further, therefore, to sippose that analogous bacteria, or symbiotes, ma have a like function in the nutrition of animals. It is supposed that the symbiotes enter the alimentary canal of men and an:mals together with their. food and the question then arises as to the method by wh:ch they become distributed in the various organs where they are found. M. Portier's theory is to the effect that this distribution occurs by means of the blood. It has been shown in recent years that be sides the red corpuscles and the white cells, or leuco cytes, the blood contains certain minute bodie termed globulins, whose origin and function has never been ascertained. These globulins exhibit striking resemblance to bacteria. They are in the shape of rods of different sizes, as if some of them were older than others. These rods readily assum the rounded coccus form quite like the mitochondria; they are most numerous in those creatures whos they are most numerous in those creatures whose
metabolism is most intense. They are markedly diminished in a state of fasting. Portier has con ceived the idea that these globulins are really sym blotes employed in the nutrition of the an:mal.

Granted that the symbiotes are concerned in $\mathrm{nu}$ they play the:r part in reproduction. A distinguished histologist, Faure Fremiet, has shown that the ovule is almost entirely lacking in mitochondria while the corresponding male element is well supplied with corresponding male element is well supplied with
them. Portier explains this by saying that the mito- chondria or symbiotes in the ovule have already undergone a transformation into reserve materials, usually fats, as described above. It will be remembered that there are numerous cases of natural or art.ficial parthenogenesis, in which the ovule devel-
ops without being fertilized. The development starts fiom a mass of matter called by histologists the vitclline body. which is of mitochondrial origin. But according to Port:er this vitelline body consists of a cluster of symbiotes which have become isolated but are not yet transformed into sacs of reserve mawhich remains to be discovered are capable of producing the development of the ovule in spite of the absence of male element which is so well supplied with symbiotes. It will be seen that this hypothesis supplies an explanation not only for natural, but also for artificial or experimental parthenogenesis, if we suppose that the ovule contains a sufficient number 0 : non-transformed symbiotes to replace those which are habitually introduced by the male element. If this be true the experimenter need only arouse by some suitable agent the symbiotes which exist therein in a quiescent state, or else to innoculate the ovule with fresh symbiotes if those already existing therein are exhausted.

One advantage of the theory of symbiotes, according to its author, is that it agrees admirably with the "Unicist" theory of life. The view was held by Liebig and J. B. Dumas that the nutrition of animals differs in nature from that of plants, the latter making use of immediate principles by means of synthesis and reduction while animals destroy and oxid:se the materials elaborated by vegetable life. In other words the animal merely makes use of building blocks which have been constructed by plants from inorganic matter. This theory was vigorously combated by Claude Bernard, in whose opinion analysis and synthesis are inseparable-the two phenomena and synthesis are inseparable-the two phenomena
teing co-existent in all living organisms. This view is termed the Unicist theory. The intervention of symbiotes, "wh:ch are derived from the same stock and wh:ch are, perhaps. identical, or which at any rate consist of very similar species in all living creathe great physiologist.

If symbiotes wear out and grow old through their activities and their transformations and if they are ind ispensable to the organ:sm, it is evident that the latter cannot survive unless the supply of young symtiotes is constantly renewed from without; hence if the food fails to contain the necessary supply of symb:otes the organism is in jeopardy, a view which accords with what has already been said concerning accords with what has al
vitamines and symbictes.

Animals fed upon aseptic food which has not been heated thrive perfectly; they also thrive upon food which has been slightly heated, even when the heating has been repeated several times, prov'ded the temperature is not too high. But as soon as the temperature of boil'ng water is reached some foods become injurious, while all are harmful after be'ng heated to $120^{\circ} \mathrm{C}$. $\left(248^{\circ} \mathrm{F}\right.$.). In other words a food which has been certainly sterilized by heat is a food which may still retain its physiolog:cal, but not its biological value. M. Portier believes that it is the destruction of the symbiotes which has thus depreciater the value of the food. The aseptic life is pcssible when symbiotes are present, as in the case of the tunnel-making caterpillars referred to above, but is imposs:ble without symbiotes. But it must not be forgotten that the symbiotic condition is a state of normal physiological association. which should not be confused with the septic condition which is a state of abnormal and pathological association.

It has heen proved, however, that certain animals exist which are capable of living upon food which is entirely free from sym saying that in all cases where the organism seems to feed upon aliment wh'ch are the organism seems to feed upon aliment which are
deprived of symbiotes, it is nourished in reality by a "transformator" which intervenes het ween the feeder and the food-usually by a pungus which contains symbiotes. There are certain coleoptera whicb live upon the wood of trees in which they excavate they live upon the wood itself, which la lacking in symbiotes. In reality, however. It is a fungus of the genus Ambrosia which lives upon the wood. and this genus Ambrosia which lives upon the wood. and this
fungus contains symhiotes. The wood which is infungus contains symhiotes. The wood which is in
digestible for the Insect is digested by the pungus, after which the insect feeds upon the transformator fungus. Another example is of the termite, wh:ch swallows. It seems to live upon the wood, but this is accomplished in a very curious manner. It collects its own excreta and agglomerates them into sher:cal granules, forming a sort of cake. When hese cakes are examined minutelý they are seen to be filled w:th the mycelium of a fungus which produces spores here and there. In an occuped ant hill only th:s mycelium is seen, but in a deserted hil there issues from the mycelium a sort of down 4 or $5 \mathrm{~mm}$. in height. The fact is that the ants graze, so to speak, upon this growth, and thus keep it cut short. In real:ty, therefore, they swallow the wood merely to prepare a suitable soil for the fungus, which is their actual food supply.

Even more curious is the case of the wood-eating caterpillars of the genera Cossus. Sesia. Nonagria. Zeuzera. These do devour wool indeel, but whe the ligneous paste in the alimentary canal is exam ined it is found to be filled with micro-organ:sms, particularly with the con:d:a of a fungus of the genus Isaria, and it is the spores of this fungus which form the food of the insects. These spores, which contain symbiotes, are absorbed by the epithel:a cells and the leucocytes. There are even cases in which the intermediary fungus is cultivated neithe outside the animal nor in the alimentary canal, hut $n$ its very tissues. An example of this is the ordinary aphis or plant louse. This seems to suck the juices of the plant which it pricks. However, it sucks them in through a sort of filter, through wh ch it is impossible for symbiotes to pass. But M. Portier explains that the aphis possesses two lumps of a brown or green substance at one s:de of the intestine, which are filled with bacteriodal bodies which form a mycetome, i.e., a mass of yeast cells. The nature of this green mass has been much debated. Portier considers it merely a collection of symbiotes -a fungus living upon the juices drawn from plants and prov:ded with symbiotes. It is this fungus. he believes, which is the real food of the lice; the latter suck the plant juice to nourish the fungus, which in turn nourishes them.

BYMROSIS IN PLANTS

Certain plants also exhibit a state of symbios's The seeds of orchids, entirely lacking in the reserves of alimentary substances for the young plant, which most seeds contain, are incapable of germination when sown upon sterile ground. but readily germinate upon soil where orchids have previously been cultivated for the reason that in this case the teguments are invadet by a fungus of the genus Rhiroctonio. The ce'ls of the orchid digest the mycelium of the fungus ant Portier. therefore. regards the orchid as being epixylous in a manner similar to the cytases which attack the wood: it develops by feeding upon the nutritive matters thus elaborated and it then becomes a source of food supply for the plan'. to which i' $\mathrm{g}$ ves over the symbiotes. In the orchid this symb osis is usually not hereditary, i.e., the symbote does not exist in the oet: as it exists in the egg of xylophagous animalsnature roties unon the stmbiotes of the soil to surply the seed. In the Neottia. however. the parasitic fungus pesses into the seed. Similarly the mycorhizes of many plants merely represent a case of the syduliosis of a fungus and a plant of h:gher order.

BTMmotes AND DISFASE

It will he remembered that the minute hod'es in th. i) jod know: as glohulins are looked upon bj Portier merely as,crculating symbiotes. If this be $t$.ue it is possible that they take part in the de. feace of the crganism through the production of im munity. A number of recent researches has shown that the globulins are probahly concerned in the genesis of alexine and of the anti-hod'es and also in the elimination of hacteria, especially staphylococci. It has been observed. too. that in a condition of anaphylaxia, !.e., the partial or total incanactty of the organism to react against the introduction of infu$\therefore$ us sibstances, the glohulins are almost entirely lacis'ng. 3 In' $^{\prime}$ it is suggested that if some means can be found to increase the multiplication of the globulins in :estion may thus he combated.

We will not here discuss Portipr's thenry of the possible connection between symbiotes and cancer since much mo e work along $r$ is ine is needed either to substantiate or to disprove his viervs. In tlie same way the hypothetical connection hetween srmbiotic action and the sudden variation of species known as mutation though provocative of interest can here be merely mentionet. 